\section{Positive Supports}

Orlando Sánchez ${ }^{1}$ and Martha Brownlee-Duffeck ${ }^{2}$ ${ }^{1}$ Minneapolis VA, Minneapolis, MN, USA ${ }^{2}$ Harry S. Truman Memorial, Columbia, MO, USA

\section{Synonyms}

Positive behavior interventions and supports; Positive behavioral supports

\section{Definition}

Positive supports is an empirically based and holistic approach that focuses on behavioral interventions to increase skills and improve quality of life, as opposed to suppress or punish undesired behaviors (AAIDD 2010; APBS 2015). The purpose is to teach appropriate behaviors with contextual factors in mind. Strategies are intended to change systems (e.g., family settings, classrooms, etc.) into environments that foster learning and positive functioning. The concept has its roots in applied behavioral analysis and is applicable to a wide range of populations including those termed "severely disabled" and those with traumatic brain injury (Ylvisaker and Feeney 2007; Sailor 2009).

\section{Cross-References}

- Applied Behavioral Analysis

- Behavior Management

- Behavior Modification

\section{References and Readings}

American Association on Intellectual and Developmental Disabilities. (2010). Intellectual disability: Definition, classification, and systems of support (11th ed.). Washington, DC: American Association on Intellectual and Developmental Disabilities.

APBS. Retrieved November 19, 2015., from http://www. apbs.org/index.html

Sailor, W. (2009). Handbook of positive behavior support. New York: Springer.

Ylvisaker, M., \& Feeney, T. (2007). Pediatric brain injury: Social, behavioral, and communication disability. Physical Medicine and Rehabilitation Clinics of North America, 18, 133-144. 